\title{
Study on phase transformation and band gap of organo-halide perovskite for solar cell application
}

\author{
Priyabrata Sadhukhan, Apurba Ray, Atanu Roy and Sachindranath Das* \\ Department of Instrumentation Science, Jadavpur University, Kolkata-700032, India \\ *Email: sachindas15@gmail.com
}

Hybrid organo-metal halide perovskites has proven itself a potential alternative to eliminate old silicon based solar cells in terms of both power conversion efficiency and fabrication cost[1]. But this material is not environmentally robust. To rectify this problem understanding the basic material properties is very much required.

Here we have studied change of lattice structure and the band-gap of mixed halide organic perovskite where methylamine and lead contribute the cation and halogen atoms works as the anion $\left(\mathrm{CH}_{3} \mathrm{NH}_{3} \mathrm{Br}_{3-\mathrm{X}} \mathrm{I}_{\mathrm{x}}\right)$.
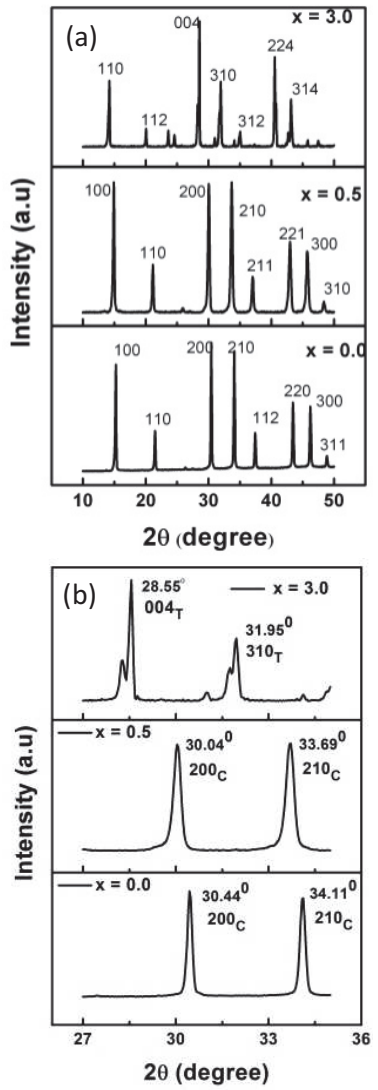

Figure 1: XRD pattern of $\mathrm{CH}_{3} \mathrm{NH}_{3} \mathrm{Br}_{3-\mathrm{X}} \mathrm{I}_{\mathrm{X}}$ (a) Cubic and (b) tetragonal phases
The materials were characterised by XRD, UVvisible and Photoluminescence measurement. We have varied the relative abundance $(\mathrm{x})$ of the two halogens (Iodine and Bromine) and found that lattice structure changes from cubic to tetragonal (Figure 1) and the band gap decreases as $\mathrm{x}$ increases (Figure 2). Change of lattice structure gives information about tensile stress and strain which may be helpful to explain the instability of the material. Information about the band gap tunability is helpful because band gap of a potential solar cell material must be tuned suitably so that it can absorb and convert the maximum energy from solar spectra to electrical energy. This band-gaptunability also makes it possible to fabricate colourful solar energy harvesting window glasses which will be both energy efficient and decorating.
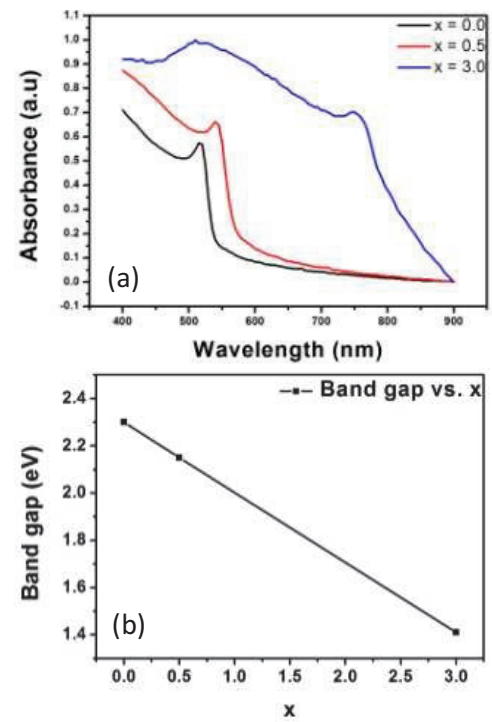

Figure 2: (a) UV-Visible spectra of $\mathrm{CH}_{3} \mathrm{NH}_{3} \mathrm{Br}_{3-\mathrm{X}} \mathrm{I}_{\mathrm{x}}$, and (b) Variation of band gap with $\mathrm{x}$

\section{References}

1. PengGao, Michael Gratzel, Mohammod K. Naziruddin, DOI: 10.1039/c4ee00942h 